\title{
Prognostic Value of Phosphotyrosine Phosphatases in Hepatocellular Carcinoma
}

\author{
Guangyan Zhangyuan ${ }^{\mathrm{a}}$ Yin Yin ${ }^{\mathrm{a}} \quad$ Wenjie Zhang ${ }^{\mathrm{b}, \mathrm{c}}$ WeiWei Yu ${ }^{\mathrm{a}}$ \\ Kangpeng Jin ${ }^{\mathrm{a}}$ Fei Wang ${ }^{\mathrm{a}}$ Ruyi Huang ${ }^{\mathrm{a}}$ Haiyuan Shen ${ }^{\mathrm{a}}$ \\ Xiaochen Wang ${ }^{\mathrm{a}}$ Beicheng Sun ${ }^{\mathrm{a}, \mathrm{b}}$
}

aLiver Transplantation Center of the First Affiliated Hospital and Department of Hepatobilliary Surgery of Drum Tower Clinical Medical College, Nanjing Medical University, Nanjing, ${ }^{b}$ Department of Hepatobiliary Surgery, The Affiliated Drum Tower Hospital of Nanjing University Medical School, Nanjing, 'Department of General Surgery, The First Affiliated Hospital of Nanjing Medical University, Nanjing, P.R. China

\section{Key Words}

Hepatocellular carcinoma • TCGA • Phosphotyrosine phosphatase • Cancer specific survival

\begin{abstract}
Background/Aims: During the occurrence and progression of hepatocellular carcinoma (HCC), phosphotyrosine phosphatases (PTPs) are usually described as tumor suppressors or proto-oncogenes, and to some degree are correlated with the prognosis of HCC. Methods: A total of 321 patients from the Cancer Genome Atlas (TCGA) database and 180 patients from our validated cohort with hepatocellular carcinoma were recruited in this study. Kaplan-Meier, univariate and multivariate Cox proportional hazards model were used to evaluate the risk factors for survival. Quantitative real-time PCR (qRT-PCR) and immunohistochemistry (IHC) were applied to detect the expression levels of PTP genes. Results: After screening the data of TCGA, we identified five PTPs as HCC overall survival related PTP genes, among which only three (PTPN12, PTPRN, PTPN18) exhibited differential expression levels in our 180 paired HCC and adjacent tissues $(P<0.001)$. Further analysis revealed that expression of PTPN18 was positively, but PTPRN was negatively associated with prognosis of HCC both in TCGA cohort and our own cohort. As to PTPN12, results turned out to be opposite according to HBV status. In detail, higher expression of PTPN12 was associated with better outcome in HBV group but worse prognosis in Non-HBV group. Conclusion: Our results suggested that PTPN12, PTPRN and PTPN18 were independent prognostic factors in HCC.
\end{abstract}

\section{Introduction}

Hepatocellular carcinoma (HCC), accounting for approximately $80 \%$ of all liver cancers $[1,2]$, has become the fifth most frequent cancer and ranks third in the commonest causes

G. Zhangyuan, Y. Yin, W. Zhang and W. Yu contributed equally to this work.

Beicheng Sun, M.D., Ph.D.

KARGER
Liver Transplantation Center of the First Affiliated Hospital and Department of Hepatobilliary Surgery of Drum Tower Clinical Medical College, Nanjing Medical University,. Nanjing, Jiangsu Province (China)

Tel. 86-025-86560946, Fax. 86-025-86560946, E-Mail sunbc@njmu.edu.cn 


\section{Cellular Physiology Cell Physiol Biochem 2018;46:2335-2346 \begin{tabular}{l|l} 
and Biochemistry Published online: May 09, 2018 & $\begin{array}{l}\text { (c) 2018 The Author(s). Published by S. Karger AG, Basel } \\
\text { www.karger.com/cpb }\end{array}$
\end{tabular} Zhangyuan et al.: Prognostic Value of Ptps in HCC}

of cancer-related mortality worldwide [3-5]. As a result, HCC has drawn greater attention and regular surveillance has been conducted in high risk population, which leads to an increasing number of patients who can be diagnosed at an early stage and get access to surgical treatment [6]. However, for those who undergo surgical resections, the recurrence rates are as high as 65\%-80\% in 5 years even, which results in a 5-year survival of about $40 \%$ [7-9]. Therefore, it will benefit a lot if we are capable of estimating the prognosis in clinical treatment of HCC.

As we know, during the multistep process of human HCC pathogenesis, countless components undergo complicated changes and interact with each other, among which the phosphorylation of tyrosine residues plays a significant role in several important signaling pathways, consequently regulating cell proliferation, adhesion, and migration [10,11]. It has been reported that the human "PTPome" contained 107 PTPs, which are grouped into four families based on the amino acid sequence of their catalytic domains, and almost all PTPs are part of the Class I cysteine-based family (99 genes) [12].

Studies initiated on phosphotyrosine phosphatases (PTPs) have naturally predicted that PTPs may function as tumor suppressors, and are relevant to clinicopathological features and prognosis of HCC [13-17]. However, an increasing amount of evidence suggested that PTPs could also function as oncoproteins during the progress of tumors $[18,19]$. To figure out the relationship between PTPs and prognosis of HCC, we consulted the Cancer Genome Atlas (TCGA, https://cancergenome.nih.gov/), a database for cancer gene information, and finally focused on five genes in PTP groups, which are PTP4A2, PTPN12, PTPRB, PTPRN, PTPN18. In this study, we aimed to examine the expression of these five genes in HCC, and correlate the findings with clinicopathological parameters and outcome.

\section{Materials and Methods}

\section{Patients and tissues}

For the TCGA cohort, gene expression of PTPs and clinical data of TCGA database are available from the website of Cancer Genomics Browser of University of California Santa Cruz (UCSC) (https://genome-cancer. ucsc.edu/). Only primary hepatocellular carcinoma (HCC) patients with complete overall survival data were included in this study. Follow-up was completed on Dec 30, 2016.

The validated cohort consists of 180 patients with primary HCC, whose fresh HCC tissue samples and paired adjacent non-tumor tissue samples were obtained between 2008 to 2010. They were recruited from the Liver Transplantation Center of the First Affiliated Hospital, Nanjing Medical University (Nanjing, PR China). There was no recruitment restriction on age, gender, tumor stage and no previous history of other cancers for all patients. All patients underwent hepatic resection within 2 months after diagnosis and no other anticancer treatment before surgery.

\section{Survival Data}

The overall survival (OS) was defined as the time from date of diagnosis to death due to any cause. The disease free survival (DFS) was defined as the time from date of diagnosis to date of tumor recurrence, progression or metastasis of HCC. The median follow-up of TCGA cohort and the validated cohort was 561 days (1-3675) and 22 months (1-87) respectively.
Table 1. Detail information of primers and antibodies

\begin{tabular}{lll}
\hline Gene name & & Sequence \\
\hline PTP4A2 & Forward Primer & AGAAGGGGAGCGTTCAATTCC \\
& Reverse Primer & CTCTGAAGCGTAATCGCATCTTA \\
PTPN12 & Forward Primer & AGTTGCCTTGTTGAAGGGGAT \\
& Reverse Primer & AGAAGGTGTCAAGATGGGTGG \\
PTPRB & Forward Primer & ACAACACCACATACGGATGTAAC \\
& Reverse Primer & CCTAGCAGGAGGTAAAGGATCT \\
PTPRN & Forward Primer & CATGCCCGCATAAAACTGAAGG \\
& Reverse Primer & CGAGGGTCATGCTCAATAATGG \\
PTPN18 & Forward Primer & AGGAGTCCCGTTCTGTGTACC \\
& Reverse Primer & TGCCTCACATAATCCACGGTG \\
Actb & Forward Primer & CATGTACGTTGCTATCCAGGC \\
& Reverse Primer & CTCCTTAATGTCACGCACGAT \\
Name & Catalog\# & Company \\
PTPN18 Antibody & 17551-1-AP & Proteintech \\
IA-2/PTPRN Antibody & $10584-1-A P$ & Proteintech \\
Anti-PTPN12 antibody & ab76942 & Abcam
\end{tabular}




\section{Cellular Physiology Cell Physiol Biochem 2018;46:2335-2346 \begin{tabular}{l|l} 
and Biochemistry Published online: May 09, 2018 & $\begin{array}{l}\text { Do } 2018 \text { The Author(s). Published by S. Karger AG, Basel } \\
\text { www.karger.com/cpb }\end{array}$ \\
\hline
\end{tabular} \\ Zhangyuan et al.: Prognostic Value of Ptps in HCC}

RNA isolation and quantitative real-time PCR ( $q R T-P C R$ )

RNAs were extracted from samples by using TRIzol reagent (Invitrogen, Grand Island, NY, USA) as described by the manufacturer, and were reverse transcripted using the PrimeScript RT Master Mix (Takara, Dalian, China). The SYBR Premix Ex Taq (Takara, Dalian, China) was used to perform quantitative real-time PCR on the ABI Prism 7900HT (Applied Biosystems, Foster City, CA, USA). The primer sequences were shown in Table 1.

\section{Immunohistochemistry (IHC)}

The UltraSensitiveTM SP (Mouse/Rabbit) IHC Kit (Maixin Biotech, Fuzhou, China) which uses streptavidin-biotin amplification method was applied to perform immunohistochemical study. After deparaffinizing the $4 \mu \mathrm{m}$ tissue samples, we blocked endogenous peroxidase activity with $0.3 \%$ hydrogen and incubated sections with $0.03 \mathrm{~mol} / \mathrm{l}$ citrate buffer ( $\mathrm{pH} \mathrm{6.0)}$ ) in a pressure cooker under $121^{\circ} \mathrm{C}$. Nonspecific reaction was blocked by using $10 \%$ bovine serum (Biosharp, Hefei, China) for $30 \mathrm{~min}$. Finally, sections were incubated with primary antibody overnight at $4^{\circ} \mathrm{C}$ and in turn detected with $3.3^{\prime}$-diaminobenzidine (DAB) solution. The primary antibodies we used were listed in Table 1.

\section{Evaluation of PTPN12, PTPRN, PTPN18 expression in validated cohort}

The immunohistochemically stained tissue sections were scored separately by two pathologists blinded to the clinicopathological parameters. The staining intensity was scored as 0 (negative), 1 (weak), 2 (medium) or 3 (strong). Extent of staining was scored as $0(<5 \%), 1(5-25 \%), 2$ (26-50\%), 3 (51-75 \%) and $4(>75 \%)$ according to the percentages of the positive staining areas in relation to the whole carcinoma area. Scores for staining intensity and percentage positivity of cells were then multiplied to generate the immunoreactivity score (IRS) for each case. Samples having a final staining score of $\leq 4$ were considered to be low and those with score of $>4$ were considered to be high.

\section{Statistical Analysis}

We presented categorical variables as frequency (\%), and continuous variables as median (interquartile range). Patients in TCGA cohort were divided into high-expression group and low-expression group according to the median of different PTPs expression at mRNA level. Patients in validated cohort were divided into low (IRS $\leq 4)$ and high (IRS> 4) PTP expression groups according to the immunoreactivity scores of PTPN12, PTPRN and PTPN18 respectively. X-tile 3.6.1 software (Yale University, New Haven, CT, USA) was used to determine the optimal cut-off values for PTPN12 expression in subgroup analysis for TCGA cohort [20]. The relationship between expression of the PTPs and various clinicopathological parameters was analyzed by the $\chi 2$ test and Student's t test. The log rank test was employed for the analysis of Kaplan-Meier curves. Clinical characteristics that showed significant association with survival in univariate analysis $(\mathrm{P}<0.05)$ were entered into multivariate analysis, which was performed with Cox proportional hazard model. All statistical analyses were conducted with the statistical software package SPSS for Windows, version 17 (SPSS, Inc). P $<0.05$ was considered statistically significant.

\section{Results}

\section{Clinical factors in TCGA cohorts}

A total of 321 hepatocellular carcinoma (HCC) patients were identified from TCGA cohort, among which 214 (66.7\%) were male and 107 (33.3\%) were female. The median age was 62, ranging from 17 to 90 years old. Patient demographics and pathologic features are summarized in Table 2.

Table 2. Clinicopathological features of patients with hepatocellular carcinoma in TCGA cohort

\begin{tabular}{lrr}
\hline Characteristic & N & $\%$ \\
\hline Age & $62(17-90)$ & \\
$<40$ & 21 & 6.5 \\
$40-60$ & 125 & 38.9 \\
$61-80$ & 166 & 51.7 \\
$>80$ & 9 & 2.8 \\
Gender & & \\
Male & 214 & 66.7 \\
Female & 107 & 33.3 \\
Pathologic stage & & \\
I-II & 231 & 72.0 \\
III-IV & 68 & 21.2 \\
unknown & 22 & 6.9 \\
Pathologic T & & \\
T0, T1, T2 & 248 & 77.3 \\
T3-T4 & 71 & 22.1 \\
unknown & 2 & 0.6 \\
Vascular_tumor_cell_invasion & & \\
None & 186 & 57.9 \\
Micro & 85 & 26.5 \\
Macro & 14 & 4.4 \\
unknown & 36 & 11.2 \\
\hline & & \\
\hline & & \\
& & \\
& & \\
& & \\
& &
\end{tabular}


PTPN12, PTPRN, PTPN18, PTP4A2 and $P T P R B$ were independent prognostic factors for OS in the TCGA cohort

Considering the approximately normal distribution of the expression levels of PTPs in TCGA cohort, we chose median as the cut-off for the preliminary screening, In univariate Cox proportion hazard ratio analysis, age, pathologic stage, pathologic $\mathrm{T}$, vascular tumor cell invasion, PTP4A2, PTPRN, PTPRB, PTPRO, PTPN12, PTPN18 were significantly associated with OS of HCC patients in the TCGA cohort $(\mathrm{P}<0.05)$. Multivariate analysis after adjustment for all these potential prognostic factors identified in univariate analysis demonstrated that age (HR=1.020, 95\% CI 1.003-1.037, $\mathrm{P}=0.02)$, pathologic $\mathrm{T}$ (T3-T4/T0,T1,T2) $(\mathrm{HR}=5.443,95 \%$ CI $1.785-16.596, \mathrm{P}=$ 0.011), PTP4A2 (HR=1.617, 95\%CI 1.0362.524, $\quad \mathrm{P}=0.02), \quad \mathrm{PTPN} 18 \quad(\mathrm{HR}=0.579$, 95\%CI 0.394-0.904, $\mathrm{P}=0.02), \quad$ PTPN12 $(\mathrm{HR}=1.778,95 \% \mathrm{CI} 1.136-2.783, \mathrm{P}=0.012)$, PTPRB (HR=0.514, 95\% CI 0.336-0.786, $\mathrm{P}=0.002)$ and PTPRN (HR=1.895, 95\% CI 1.259-2.851, $\mathrm{P}=0.002$ ) were independent predictors of OS (Table 3). The corresponding Kaplan-Meier curves of five PTPs are shown in Fig. 1.

Expression of PTPN12, PTPRN and PTPN18 exhibited significant difference in HCC and paired adjacent tissues in validated cohort

To verify the reliability of TCGA results, information of 180 in-house eligible patients from the Liver Transplantation Center of the First Affiliated Hospital of Nanjing Medical University were assembled and analyzed as the validated cohort, among which 137 (76.1\%) were male patients and 43 (23.9\%) were female. Detailed information of age, Hepatitis B surface antigen (HbsAg) status, ALT, AFP, cirrhosis, vascular invasion, tumor size and Edmondson grade are shown in Table 4.

To further evaluate the clinical value of five candidate PTPs in HCC, quantitative qPCR and immunohistochemistry (IHC) were performed. Compared to adjacent non-tumor tissues, PTPN12 and PTPN18 were significantly downregulated, while PTPRN was upregulated in HCC tissues
Table 3. Univariate and multivariate Cox proportional hazards analysis of OS for patients with HCC in the TCGA cohort

\begin{tabular}{|c|c|c|c|c|}
\hline Characteristic & $\mathrm{HR}(95 \% \mathrm{CI})$ & $\mathrm{P}$ & $\mathrm{HR}(95 \% \mathrm{Cl})$ & $P$ \\
\hline Age & $1.017(1.001-1.033)$ & 0.040 & $1.020(1.003-1.037)$ & 0.020 \\
\hline \multicolumn{5}{|l|}{ Gender } \\
\hline Male & 1.000 & 0.122 & & \\
\hline Female & $1.361(0.921-1.010)$ & & & \\
\hline Pathologic stage & & 0.005 & & 0.134 \\
\hline I-II & 1.000 & & 1.000 & \\
\hline III-IV & $1.851(1.207-2.838)$ & & $0.342(0.107-1.097)$ & \\
\hline unknown & $2.094(1.069-4.102)$ & & $0.810(0.314-2.085)$ & \\
\hline Pathologic T & & 0.003 & & 0.011 \\
\hline $\mathrm{T} 0, \mathrm{~T} 1, \mathrm{~T} 2$ & 1.000 & & 1.000 & \\
\hline T3-T4 & $2.031(1.349-3.058)$ & & $5.443(1.785-16.596)$ & \\
\hline unknown & $1.899(0.262-13.639)$ & & $3.441(0.347-34.138)$ & \\
\hline Vascular_tumor_cell_invasion & & 0.043 & & 0.622 \\
\hline None & 1.000 & & 1.000 & \\
\hline Micro & $1.182(0.731-1.911)$ & & $1.000(0.601-1.665)$ & \\
\hline Macro & $2.489(1.127-5.496)$ & & $1.513(0.648-3.530)$ & \\
\hline unknown & $1.760(1.034-2.999)$ & & $1.348(0.751-2.419)$ & \\
\hline PTP4A2 & $1.749(1.177-2.599)$ & 0.006 & $1.617(1.036-2.524)$ & 0.034 \\
\hline PTPRN & $1.699(1.149-2.512)$ & 0.008 & $1.895(1.259-2.851)$ & 0.002 \\
\hline PTPRB & $0.606(0.411-0.893)$ & 0.011 & $0.514(0.336-0.786)$ & 0.002 \\
\hline PTPRO & $1.622(1.098-2.394)$ & 0.015 & $1.280(0.803-2.040)$ & 0.299 \\
\hline PTPN12 & $1.550(1.052-2.283)$ & 0.027 & $1.778(1.136-2.783)$ & 0.012 \\
\hline PTPN18 & $0.643(0.434-0.953)$ & 0.028 & $0.579(0.394-0.904)$ & 0.020 \\
\hline PTPRF & $1.258(0.979-1.617)$ & 0.073 & & \\
\hline PTPRZ1 & $1.418(0.963-2.086)$ & 0.077 & & \\
\hline PTPRR & $0.882(0.762-1.021)$ & 0.092 & & \\
\hline PTPRQ & $1.100(0.980-1.234)$ & 0.105 & & \\
\hline PTP4A1 & $0.841(0.675-1.0467)$ & 0.121 & & \\
\hline PTPN23 & $1.316(0.886-1.956)$ & 0.174 & & \\
\hline PTPN3 & $0.879(0.722-1.069)$ & 0.197 & & \\
\hline PTPDC1 & $1.158(0.920-1.457)$ & 0.210 & & \\
\hline PTPRJ & $0.820(0.601-1.119)$ & 0.210 & & \\
\hline PTPN6 & $0.816(0.590-1.128)$ & 0.218 & & \\
\hline PTPLA & $1.059(0.966-1.161)$ & 0.220 & & \\
\hline PTPN22 & $0.925(0.817-1.048)$ & 0.222 & & \\
\hline PTPLAD1 & $0.872(0.692-1.100)$ & 0.247 & & \\
\hline PTPN7 & $0.931(0.819-1.058)$ & 0.274 & & \\
\hline PTPN5 & $0.917(0.781-1.077)$ & 0.289 & & \\
\hline PTPRCAP & $0.818(0.556-1.204)$ & 0.309 & & \\
\hline PTP4A3 & $1.059(0.939-1.195)$ & 0.349 & & \\
\hline PTPN14 & $1.073(0.9252-1.245)$ & 0.350 & & \\
\hline PTPMT1 & $1.190(0.795-1.782)$ & 0.398 & & \\
\hline PTPN9 & $0.858(0.594-1.240)$ & 0.416 & & \\
\hline PTPRH & $0.969(0.896-1.048)$ & 0.427 & & \\
\hline PTPRE & $1.061(0.916-1.228)$ & 0.430 & & \\
\hline PTPRD & $1.031(0.954-1.115)$ & 0.433 & & \\
\hline PTPRC & $0.954(0.846-1.077)$ & 0.449 & & \\
\hline PTPN1 & $1.125(0.810-1.564)$ & 0.482 & & \\
\hline PTPN20B & $0.970(0.885-1.063)$ & 0.519 & & \\
\hline PTPN2 & $0.922(0.685-1.241)$ & 0.594 & & \\
\hline PTPN4 & $1.091(0.784-1.516)$ & 0.606 & & \\
\hline PTPLAD2 & $1.038(0.882-1.222)$ & 0.655 & & \\
\hline PTPRM & $1.037(0.878-1.226)$ & 0.665 & & \\
\hline PTPN13 & $1.018(0.925-1.121)$ & 0.710 & & \\
\hline PTPN21 & $0.967(0.795-1.176)$ & 0.735 & & \\
\hline PTPN11 & $1.045(0.808-1.351)$ & 0.736 & & \\
\hline PTPRT & $1.015(0.926-1.113)$ & 0.748 & & \\
\hline PTPRVP & $1.030(0.840-1.263)$ & 0.777 & & \\
\hline PTPRK & $0.966(0.752-1.242)$ & 0.789 & & \\
\hline PTPRA & $1.055(0.691-1.608)$ & 0.805 & & \\
\hline PTPRN2 & $0.981(0.844-1.141)$ & 0.807 & & \\
\hline PTPLB & $1.008(0.925-1.098)$ & 0.855 & & \\
\hline PTPRU & $1.008(0.899-1.131)$ & 0.892 & & \\
\hline PTPRG & $1.007(0.862-1.178)$ & 0.926 & & \\
\hline PTPRS & $1.002(0.933-1.078)$ & 0.949 & & \\
\hline
\end{tabular}


$(n=180)$, the results of which were both confirmed at mRNA level and protein level (Fig. 2A and Fig. 2B).

PTPN12, PTPRN and PTPN18 were independent prognostic factors for $\mathrm{OS}$ and DFS in the validated cohort

For more accurate clinical analysis, patients were divided into low (IRS $\leq 4)$ and high (IRS> 4) PTP expression groups according to the immunoreactivity scores (IRS) of PTPN12, PTPRN and PTPN18 respectively (Fig. $3 \mathrm{~A})$. In the validated cohort, PTPN12 expression was associated with HbsAg status, AFP, tumor size and Edmondson grade $(\mathrm{P}<0.05)$, PTPRN expression was associated with vascular invasion, tumor size $(\mathrm{P}<0.05)$, whereas PTPN18 expression was correlated with gender, ALT and Edmondson grade $(\mathrm{P}<0.05)$ (Table 4). Univariate
Table 4. Clinicopathological features of patients with hepatocellular carcinoma in validated cohort. HBsAg: Hepatitis B surface antigen. ALT: Alanine Aminotransferase.AFP: Alpha Fetal Protein

\begin{tabular}{|c|c|c|c|c|c|c|c|c|c|c|}
\hline \multirow{2}{*}{ Clinicopathological features } & & \multicolumn{2}{|c|}{ PTPN12 } & \multirow{2}{*}{$\begin{array}{c}P \\
\text { value }\end{array}$} & \multicolumn{2}{|c|}{ PTPRN } & \multirow{2}{*}{$P$ value } & \multicolumn{2}{|c|}{ PTPN18 } & \multirow{2}{*}{$P$ value } \\
\hline & & Low & High & & Low & High & & Low & High & \\
\hline Gender & & & & 0.235 & & & 0.206 & & & 0.047 \\
\hline Male & 137 & 81 & 56 & & 46 & 91 & & 90 & 47 & \\
\hline Female & 43 & 21 & 22 & & 19 & 24 & & 21 & 22 & \\
\hline Age & & & & 0.925 & & & 0.371 & & & 0.962 \\
\hline$\leq 60$ & 117 & 66 & 51 & & 45 & 72 & & 72 & 45 & \\
\hline$>60$ & 63 & 36 & 27 & & 20 & 43 & & 39 & 24 & \\
\hline HbsAg & & & & 0.022 & & & 0.584 & & & 0.350 \\
\hline negative & 14 & 12 & 2 & & 6 & 8 & & 7 & 7 & \\
\hline positive & 166 & 90 & 76 & & 59 & 107 & & 104 & 62 & \\
\hline $\operatorname{ALT}(U / L)$ & & & & 0.514 & & & 0.251 & & & 0.049 \\
\hline$\leq 45$ & 95 & 56 & 39 & & 38 & 57 & & 65 & 30 & \\
\hline$>45$ & 85 & 46 & 39 & & 27 & 58 & & 46 & 39 & \\
\hline $\operatorname{AFP}(\mathrm{ng} / \mathrm{ml})$ & & & & 0.042 & & & 0.698 & & & 0.066 \\
\hline$\leq 13.6$ & 36 & 15 & 21 & & 12 & 24 & & 27 & 9 & \\
\hline$>13.6$ & 144 & 87 & 57 & & 53 & 91 & & 84 & 60 & \\
\hline Cirrhosis & & & & 0.982 & & & 0.118 & & & 0.059 \\
\hline absent & 46 & 26 & 20 & & 21 & 25 & & 23 & 23 & \\
\hline present & 134 & 76 & 58 & & 44 & 90 & & 88 & 46 & \\
\hline Vascular invasion & & & & 0.933 & & & 0.026 & & & 0.017 \\
\hline absent & 64 & 36 & 28 & & 30 & 34 & & 32 & 32 & \\
\hline present & 116 & 66 & 50 & & 35 & 81 & & 79 & 37 & \\
\hline Tumor size $(\mathrm{cm})$ & & & & 0.009 & & & 0.362 & & & 0.070 \\
\hline$\leq 5$ & 66 & 29 & 37 & & 21 & 45 & & 35 & 31 & \\
\hline$>5$ & 114 & 73 & 41 & & 44 & 70 & & 76 & 38 & \\
\hline Edmondson grade & & & & 0.007 & & & 0.026 & & & 0.074 \\
\hline I-II & 105 & 50 & 55 & & 45 & 60 & & 59 & 46 & \\
\hline III-IV & 75 & 51 & 24 & & 20 & 55 & & 52 & 23 & \\
\hline
\end{tabular}

Cox proportion hazard ratio analysis indicated that gender, cirrhosis, vascular invasion, tumor size, Edmondson grade were potential prognostic factors in terms of both OS and DFS (Table 5). Further multivariate analysis after adjustment suggested that expression levels of PTPN12, PTPN18, PTPRN were three independent predictors of both OS (PTPN12 high, HR: 0.461, 95\%CI 0.322-0.660, $\mathrm{P}<0.001$, PTPN18 high, HR: 0.495, 95\%CI 0.346-0.710, $\mathrm{P}<0.001$, PTPRN high, HR: 1.788, 95\%CI 1.247-2.562, P<0.001) and DFS (PTPN12 high, HR: 0.683, 95\%CI 0.469-0.994, P<0.001, PTPN18 high, HR: 0.580, 95\%CI 0.380-0.885, $\mathrm{P}<0.001$, PT-

Fig. 1. Influence of PTPN12, PTPRN, PTPN18 PT$\mathrm{PRB}$ and PTP4A2 expression patterns on overall survival (OS) by Kaplan-Meier analysis in TCGA cohort. (A) PTPN12, $\mathrm{P}=0.0255$, (B) PTPRN, $\quad \mathrm{P}=0.0469$, (C) PTPN18, $\mathrm{P}=0.0333$, (D) PT$P R B, P=0.0105$, (E) PTP4A2, $\mathrm{P}=0.0051$.
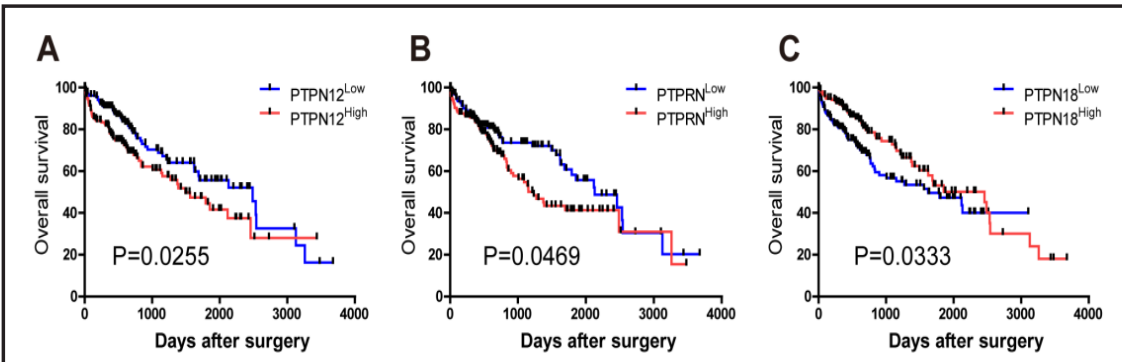

D

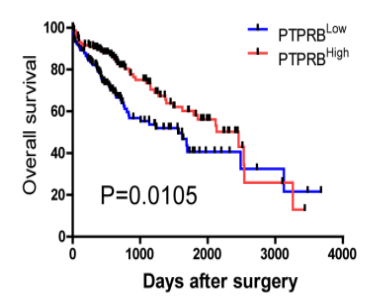

E

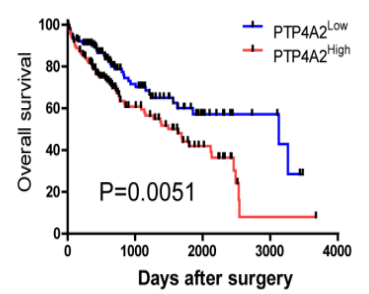


Fig. 2. Expression of PTPN12, PTPRN and PTPN18 in HCC and the paired adjacent tissues. (A) Relative expression of PTPN12, PTPRN and PTPN18 in HCC and the paired adjacent tissues measured with qPCR. The data were normalized to $\beta$-actin, calculated by $2^{-\triangle \Delta \mathrm{CT}}$, transformed to log form and presented as mean \pm SD $(n=180) .{ }^{* * *} \mathrm{p}<0.001$. (B) Representative images of IHC staining of PTPN12, PTPRN and PTPN18 in HCC and the paired adjacent tissues $(n=180)$.

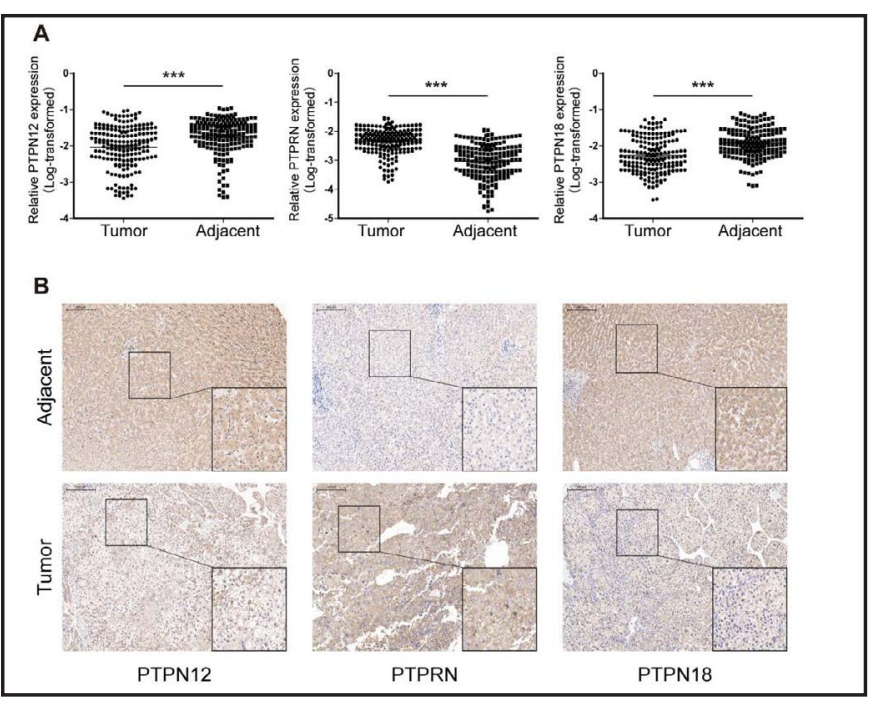

PRN high, HR: 1.598, 95\%CI 1.072-2.383, $\mathrm{P}=0.002$ ) (Table 5). This notion was also supported with KaplanMeier analysis of OS and DFS for PTPN12, PTPN18, PTPRN (Fig. 3B).

Subgroup analysis of overall survival for PTPN12 according to HBV status in TCGA cohort

As shown in Fig. 1B, $3 \mathrm{~B}$, we got diametrically opposed results in term of PTPN12, which has been reported as a HBV associated protein [15, 21-23]. Moreover, the majority of patients from the TCGA cohort were at the risk of Hepatitis C, Nonalcoholic Fatty Liver Disease (NAFLD) or excessive alcohol consumption, while almost all patients of our validated cohort are Hepatitis B infectors. Therefore, patients from TCGA cohort were redivided into
Table 5. Univariate and multivariate Cox proportional hazards analysis of OS or DFS for patients with HCC in the validated cohort

\begin{tabular}{|c|c|c|c|c|c|c|c|c|}
\hline \multirow[b]{3}{*}{ Characteristic } & \multicolumn{4}{|c|}{ Overall survival (OS) } & \multicolumn{4}{|c|}{ Disease free survival (DFS) } \\
\hline & \multicolumn{2}{|c|}{ Univariate analysis } & \multicolumn{2}{|c|}{ Multivariate analysis } & \multicolumn{2}{|c|}{ Univariate analysis } & \multicolumn{2}{|c|}{ Multivariate analysis } \\
\hline & HR $(95 \%$ CI) & P & HR (95\% Cl) & $\mathrm{P}$ & HR ( $95 \%$ Cl) & $P$ & HR ( $95 \%$ Cl) & $\mathrm{P}$ \\
\hline Age & & 0.153 & & & & 0.178 & & \\
\hline$\leq 60$ & 1.000 & & & & 1.000 & & & \\
\hline$>60$ & $1.278(0.913-1.791)$ & & & & $1.283(0.893-1.844)$ & & & \\
\hline Gender & & 0.025 & & 0.054 & & 0.034 & & 0.057 \\
\hline Male & 1.000 & & 1.000 & & 1.000 & & 1.000 & \\
\hline Female & $0.645(0.439-0.946)$ & & $0.675(0.453-1.007)$ & & $0.639(0.422-0.968)$ & & $0.658(0.427-1.013)$ & \\
\hline HbsAg & & 0.095 & & & & 0.155 & & \\
\hline negative & 1.000 & & & & 1.000 & & & \\
\hline positive & $0.615(0.347-1.089)$ & & & & $0.638(0.343-1.185)$ & & & \\
\hline ALT (U/L) & & 0.556 & & & & 0.751 & & \\
\hline$\leq 45$ & 1.000 & & & & 1.000 & & & \\
\hline$>45$ & $1.101(0.799-1.517)$ & & & & $1.058(0.748-1.496)$ & & & \\
\hline $\operatorname{AFP}(\mathrm{ng} / \mathrm{ml})$ & & 0.651 & & & & 0.565 & & \\
\hline$\leq 13.6$ & 1.000 & & & & 1.000 & & & \\
\hline$>13.6$ & $0.913(0.614-1.356)$ & & & & $0.883(0.577-1.350)$ & & & \\
\hline Cirrhosis & & 0.030 & & 0.078 & & 0.031 & & 0.079 \\
\hline absent & 1.000 & & 1.000 & & 1.000 & & 1.000 & \\
\hline present & $1.522(1.042-2.224)$ & & $1.429(0.961-2.123)$ & & $0.870(1.043-2.389)$ & & $1.474(0.955-2.274)$ & \\
\hline $\begin{array}{l}\text { Vascular } \\
\text { invasion }\end{array}$ & & 0.001 & & 0.004 & & 0.001 & & 0.004 \\
\hline absent & 1.000 & & 1.000 & & 1.000 & & 1.000 & \\
\hline present & $1.786(1.269-2.514)$ & & $1.719(1.194-2.474)$ & & $1.830(1.262-2.655)$ & & $1.781(1.199-2.645)$ & \\
\hline Tumor size $(\mathrm{cm})$ & & 0.002 & & 0.385 & & 0.017 & & 0.956 \\
\hline$\leq 5$ & 1.000 & & 1.000 & & 1.000 & & 1.000 & \\
\hline$>5$ & $1.742(1.228-2.470)$ & & $1.184(0.809-1.731)$ & & $1.571(1.084-2.278)$ & & $1.011(0.674-1.518)$ & \\
\hline Edmondson & & 0.000 & & 0.000 & & 0.000 & & 0.000 \\
\hline I-II & 1.000 & & 1.000 & & 1.000 & & 1.000 & \\
\hline III-IV & $2.468(1.774-3.434)$ & & $2.022(1.431-2.858)$ & & $2.582(1.809-3.685)$ & & $2.184(1.503-3.174)$ & \\
\hline PTPRN & $1.995(1.412-2.819)$ & 0.000 & $1.788(1.247-2.562)$ & 0.002 & $2.095(1.435-3.058)$ & 0.000 & $1.598(1.072-2.383)$ & 0.002 \\
\hline PTPN12 & $0.488(0.518-0.680)$ & 0.000 & $0.461(0.322-0.660)$ & 0.000 & $0.466(0.325-0.667)$ & 0.000 & $0.683(0.469-0.994)$ & 0.000 \\
\hline PTPN18 & $0.413(0.292-0.584)$ & 0.000 & $0.495(0.346-0.710)$ & 0.000 & $0.397(0.272-0.579)$ & 0.000 & $0.580(0.380-0.885)$ & 0.000 \\
\hline
\end{tabular}

two groups in accordance with HBV status and the optimal cut-off values of PTPN12 expression in each group were determined with X-tile 3.6.1 software (Yale University, New Haven, CT, USA). Subgroup analysis in TCGA cohort suggested that PTPN12 expression level was positively related to OS in HBV group (univariate: HR: $0.458,95 \% \mathrm{CI} 0.158-0.876, \mathrm{P}=0.015$ multivariate: HR: $0.252,95 \% \mathrm{CI} 0.076-0.832, \mathrm{P}=0.024)$, but negatively related to $\mathrm{OS}$ in nonHBV group (univariate: HR: 3.169, 95\%CI 1.748-5.748, $\mathrm{P}<0.001$ multivariate: HR: 2.972 


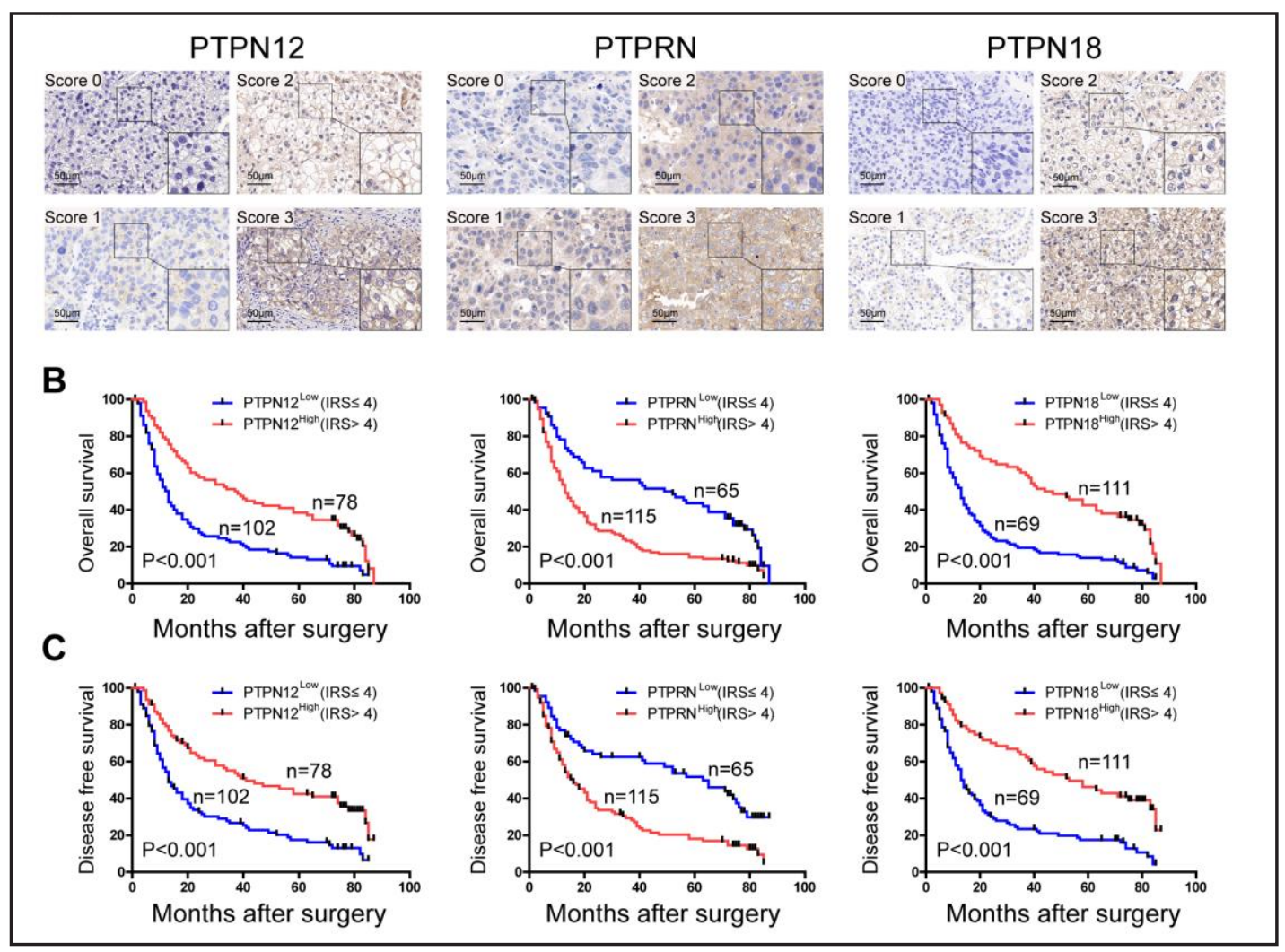

Fig. 3. Influence of PTPN12, PTPRN and PTPN18 expression patterns on overall survival (OS) and disease free survival (DFS) by Kaplan-Meier analysis in validated cohort. (A) Different scores indicate intensity of PTPN12, PTPRN and PTPN18 in representative tumor tissues. The final immunoreactivity score (IRS) were calculated by intensity and percentage of stained cells described in materials and methods.,(B-C) KaplanMeier analysis of overall survival (OS) (B) and disease free survival (DFS) (C) for PTPN12, PTPRN and PTPN18 expression.

95\%CI 1.632-5.413, $\mathrm{P}<0.001$ ) (Table 6 and Table 7). Corresponding KaplanMeier analyses were shown in Fig. 4A and $4 \mathrm{~B}$.

\section{Discussion}

HCC has turned out to be an increasingly serious problem which threatens human health worldwide [1, $24,25]$. In spite of the emerging role of interventional therapy, chemotherapy and immunotherapy, surgical resection remains the cornerstone in the treatment for HCC patients [26]. However, on account of high postoperative recurrence rate, the long-term survival is still unoptimistic, which was reported ranging from $65 \%$ to $80 \%$ in 5 -year after primary surgery
Table 6. Univariate and multivariate Cox proportional hazards analysis of OS for patients with HCC in HBV subgroup of the TCGA cohort

\begin{tabular}{|c|c|c|c|c|}
\hline \multirow[b]{2}{*}{ Characteristic } & \multicolumn{2}{|c|}{ Univariate analysis } & \multicolumn{2}{|c|}{ Multivariate analysis } \\
\hline & HR $(95 \% \mathrm{CI})$ & $P$ & HR $(95 \% \mathrm{CI})$ & $\mathrm{P}$ \\
\hline Age & $1.022(0.980-1.066)$ & 0.313 & $1.033(0.987-1.082)$ & 0.166 \\
\hline \multicolumn{5}{|l|}{ Gender } \\
\hline Male & 1.000 & 0.848 & 1.000 & 0.704 \\
\hline Female & $0.884(0.250-3.127)$ & & $0.756(0.178-3.200)$ & \\
\hline Pathologic stage & & 0.133 & & \\
\hline I - II & 1.000 & & & \\
\hline IIII-IV & $3.246(1.029-10.244)$ & & & \\
\hline \multicolumn{5}{|l|}{ unknown } \\
\hline Pathologic T & & 0.041 & & 0.122 \\
\hline $\mathrm{T} 0, \mathrm{~T} 1, \mathrm{~T} 2$ & 1.000 & & 1.000 & \\
\hline T3-T4 & $3.305(1.047-10.429)$ & & $2.900(0.752-11.179)$ & \\
\hline Vascular_tumor_cell_invasion & & 0.023 & & 0.017 \\
\hline None & 1.000 & & 1.000 & \\
\hline Micro & $4.570(1.530-13.647)$ & & $5.703(1.788-18.188)$ & \\
\hline Macro & $5.207(1.035-26.203)$ & & $8.684(1.418-53.178)$ & \\
\hline unknown & $6.941(0.821-58.668)$ & & $2.736(0.216 .-34.725)$ & \\
\hline PTPN12 & & 0.015 & & 0.024 \\
\hline Low & 1.000 & & 1.000 & \\
\hline High & $0.458(0.158-0.876)$ & & $0.252(0.076-0.832)$ & \\
\hline
\end{tabular}

\section{KARGER}


Fig. 4. Subgroup analysis of overall survival for PTPN12 according to HBV status in TCGA cohort. HCC patients in HBV group and nonHBV group were equally divided into training and validation sets. X-tile plots of training sets were shown in the left panels, with plots of matched valida-
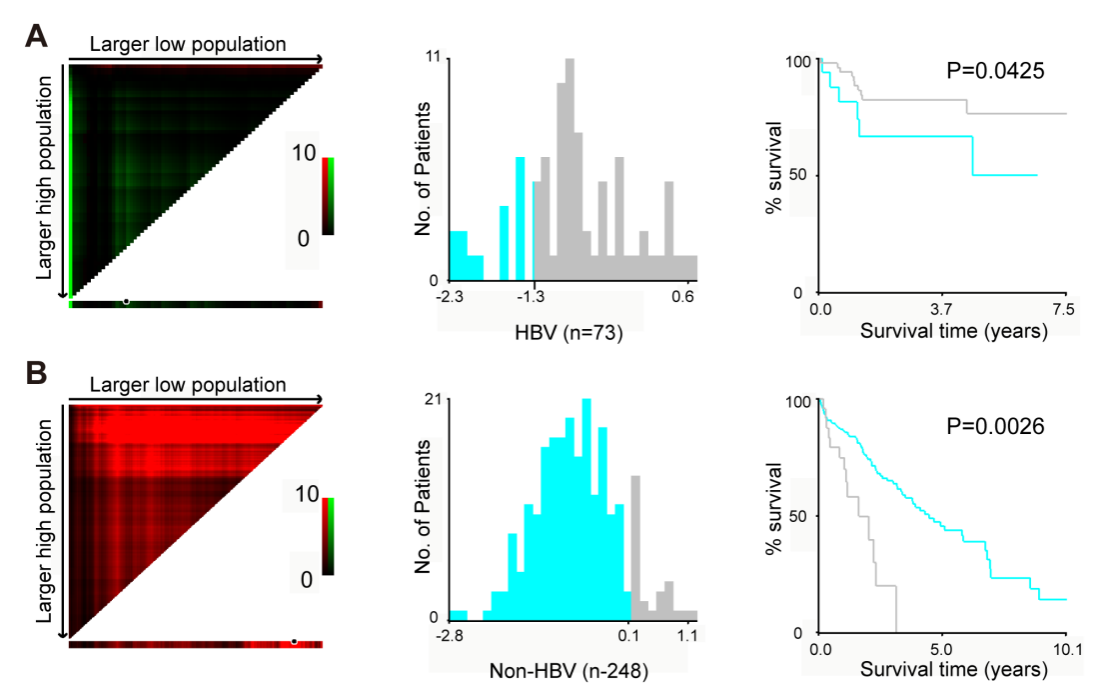

tion sets shown in

the smaller inset. The optimal cut-off values highlighted by the black circles in left panels were also shown in histograms of the entire cohort (middle panels), and Kaplan-Meier plots were displayed in right panels. P values were determined by using the cut-off values defined in training sets and applying them to validation sets. The optimal cut-off values of PTPN12 in two groups for OS were -1.5 and 0.1 respectively. (A) HBV group (n=97) (B) Non-HBV group ( $\mathrm{n}=224)$.

[27]. As a result, it increasingly becomes a new focus of research to find the methods for estimating the prognosis of HCC more accurately.

Previous study has demonstrated that PTPs functioned as tumor suppressors by removing phosphate moieties on target proteins like RPTPa and PRL family [18]. However, since Zhang SQ characterized SHP2 as the first "oncoPTP" in 2004, more oncogenic PTPs have been described during the last decade. Most of them are regarded as low molecular weight (LMW) PTPs, with a conserved signature motif, CXXXXXRS/T, in their active site, but most other sequences conserved among PTPs lacking [28, 29]. For instance, PTP (CAAX1) and PTP (CAAX2) were upregulated in epithelial cells leading to tumor growth in nude mice and a transformed phenotype in vitro [30]. Interestingly, some of the PTPs like the prototypic PTP1B have been elucidated both their pro-oncogenic and tumor-suppressing characters [18]. However, the mechanism why PTPs function differentially in carcinogenesis haven't yet been completely defined. Furthermore, compared to melanoma and breast cancer, only sporadic researches focused on HCC [31,32].

In our study, we investigated the expression levels in HCC and paired adjacent tissues of five PTPs screened from TCGA, and three of them showed significant difference. Further
Table 7. Univariate and multivariate Cox proportional hazards analysis of OS for patients with HCC in non-HBV subgroup of the TCGA cohort

\begin{tabular}{|c|c|c|c|c|}
\hline \multirow[b]{2}{*}{ Characteristic } & \multicolumn{2}{|c|}{ Univariate analysis } & \multicolumn{2}{|c|}{ Multivariate analysis } \\
\hline & HR $(95 \%$ CI) & $\mathrm{P}$ & HR $(95 \% \mathrm{CI})$ & $\mathrm{P}$ \\
\hline Age & $1.013(0.995-1.031)$ & 0.169 & $1.013(0.995-1.032)$ & 0.153 \\
\hline \multicolumn{5}{|l|}{ Gender } \\
\hline Male & 1.000 & 0.472 & 1.000 & 0.535 \\
\hline Female & $1.167(0.766-1.776)$ & & $1.144(0.748-1.748)$ & \\
\hline Pathologic stage & & 0.055 & & \\
\hline I-II & 1.000 & & & \\
\hline III-IV & $1.583(1.000-2.507)$ & & & \\
\hline unknown & $1.860(0.963-3.594)$ & & & \\
\hline Pathologic T & & 0.034 & & 0.054 \\
\hline $\mathrm{T} 0, \mathrm{~T} 1, \mathrm{~T} 2$ & 1.000 & & 1.000 & \\
\hline T3-T4 & $1.770(1.149-2.727)$ & & $1.711(1.106-2.646)$ & \\
\hline unknown & $1.596(0.220-11.570)$ & & $1.246(0.164-9.488)$ & \\
\hline Vascular_tumor_cell_invasion & & 0.160 & & \\
\hline None & 1.000 & & & \\
\hline Micro & $0.930(0.546-1.583)$ & & & \\
\hline Macro & $2.527(0.996-6.409)$ & & & \\
\hline unknown & $1.362(0.783-2.367)$ & & & \\
\hline PTPN12 & & 0.000 & & 0.000 \\
\hline Low & 1.000 & & 1.000 & \\
\hline High & $3.169(1.748-5.748)$ & & $2.972(1.632-5.413)$ & \\
\hline
\end{tabular}




\section{Cellular Physiology Cell Physiol Biochem 2018;46:2335-2346 \\ and BiOChemistry Published online: May 09, $2018 \quad$\begin{tabular}{l|l} 
DOI: 10.1159/000489625 2018 The Author(s). Published by S. Karger AG, Basel \\
www.karger.com/cpb
\end{tabular} \\ Zhangyuan et al.: Prognostic Value of Ptps in HCC}

exploration unveiled their association with clinical features, such as gender, HbsAg status, AFP, ALT, cirrhosis, vascular invasion, tumor size and Edmondson grade. More importantly, all of them were demonstrated to have impact on prognosis of HCC.

PTPN12 (Protein tyrosine phosphatase non-receptor type 12), a widely expressed mammalian cytoplasm protein, was reported as a regulator of cell adhesion and migration in several human malignancies, including HCC, breast cancer, ovarian cancer, colon cancer and esophageal squamous cell carcinoma [14, 15, 33-35]. It is rather remarkable that one of the expression quantitative trait loci (eQTL) for PTPN12 could multiplicatively interact with HBV hotspot mutation, which was suggested to significantly increase the risk of both chronic HBV infection and HBV-related HCC [21]. Moreover, PTPN12 inhibits secondary T-cell responses and is implicated in human autoimmunity, which may be either beneficial or detrimental to those infected with HBV [22, 23]. All these findings highlight the importance of PTPN12 in the development of HBV-related HCC. In our study, we came to completely opposite conclusions on the relationship between PTPN12 and prognosis in two different cohorts, subgroup analysis of TCGA cohort according to HBV status indicated that differentiation of risk factors in this two cohort might partly contribute to this discrepancy. Considering that HBV infection is still the main risk factor of HCC in China [24], it will be of dramatic significance to explore the association between the interaction of PTPN12 with HBV mutation and the repressive function of PTPN12 in HCC. Furthermore, whether PTPN12 can be targeted for clinical treatment to chronic HBV infection and be applied to terminate the inflammation-carcinoma transformation in HCC deserves extended studies.

PTPRN is a transmembrane PTP, which locates on the long arm of human chromosome 2 (2q35) [36]. Previous researches demonstrated that PTPRN was processed in secretory granule of pancreatic islets and other neuroendocrine cells, which quite possibly accounted for its significant correlation with diabetes [37]. However, the relationship between PTPRN and cancers remains illy defined. On contrary to other two PTPs in our study, PTPRN was negatively related to the survival of HCC patients, which corresponded to the data from TCGA. Therefore, all these results indicated the role of PTPRN in liver tumorigenesis, while the precise mechanism is yet to be illuminated.

PTPN18, also named BDP1, belongs to the small sub-family of PEST domain-containing PTPs. It was primarily identified as a negative regulator in tyrosine-specific phosphorylation of HER2, which was implicated in the mediation of important cellular functions like cell survival, proliferation, polarity and migration [38-40]. Recently, much attention was paid to its role in different cancers [41-43]. For instance, it was reported to suppress the invasive and metastatic ability of HER2 overexpression breast cancer, and lead to the cancer specific splice variations in thyroid cancers like FTA, FTC, and FVPTC [41, 43]. More interestingly, Meir et al. found that compared to the primary tumor, the expressions of PTPN18 as well as other six genes were up-regulated in liver metastases of uveal melanoma according to the microarray results, which indicated its involvement in distant colonization of cancer cell [44]. Though our study suggested its potential to be a tumor suppressor and prognosis indicator in HCC, more studies are required to uncover the accurate mechanism.

In spite that conclusions made from two independent cohorts were convincing owing to large sample capacity and relative long-term follow-up, certain limitations still should be considered that several prognosis-related risk factors were not included in the TCGA cohort like tumor size, chemotherapy and cirrhosis status, which might also partly contribute to the contrary results of PTPN12 in two different cohorts. Second, considering the complex network of different signal pathways in vivo, critical roles of other PTPs excluded in this study could not be denied.

Taken together, of the five genes we screened from TCGA, three showed significant difference in the expression levels between HCC and paired adjacent tissues. Expression of PTPN18 was positively, while PTPRN was negatively related to prognosis of HCC. As to PTPN12, results turned out to be opposite according to HBV status. In detail, higher expression of PTPN12 was associated with better outcome in HBV group but worse prognosis in NonHBV group. Combined with the previous studies, these findings highlight the importance of 


\section{Cellular Physiology Cell Physiol Biochem 2018;46:2335-2346 \begin{tabular}{l|l} 
DOI: 10.1159/000489625 & Ond Biochemistry 2018 The Author(s). Published by S. Karger AG, Basel \\
Published online: May 09, 2018 & wwwarger.com/cpb
\end{tabular} \\ Zhangyuan et al.: Prognostic Value of Ptps in HCC}

PTPs in the development of HCC. Nevertheless, it requires more investigations to obtain a distinct understanding about the role of PTPs in human carcinogenesis, which may indicate novel direction for not only the diagnosis and prognosis of HCC, but also the development of clinical therapeutic approaches.

\section{Abbreviations}

HCC (Hepatocellular carcinoma; PTP, phosphotyrosine phosphatase; OS, overall survival; DFS, disease free survival; TCGA, The Cancer Genome Atlas; IHC, immunohistochemistry; PCR, polymerase chain reaction; GAPDH, glyceraldehyde-phosphate dehydrogenase; PTPN12, protein tyrosine phosphatase, non-receptor type 12; PTPRN, protein tyrosine phosphatase, receptor type N; PTPN12, protein tyrosine phosphatase, non-receptor type 12; PTPRB, protein tyrosine phosphatase, receptor type B; PTP4A2, protein tyrosine phosphatase type IVA, member 2).

\section{Acknowledgements}

This work was supported by grants from the National Key Research and Development Program of China (grant number: 2016YFC0905900 to BS); The State Key Program of National Natural Science of China (81430062 to BS); National Basic Research Program of China (2012CB910800 to BS). This work was also supported in part by the program for Development of Innovative Research Team in the First Affiliated Hospital of NJMU and the Priority Academic Program of Jiangsu Higher Education Institutions. BS is Yangtze River scholars distinguished professor.

\section{Disclosure Statement}

The authors declare to have no competing interests.

\section{References}

1 Jemal A, Bray F, Center MM, Ferlay J, Ward E, Forman D: Global cancer statistics. CA Cancer J Clin 2011;61:69-90.

-2 Perz JF, Armstrong GL, Farrington LA, Hutin YJ, Bell BP: The contributions of hepatitis B virus and hepatitis C virus infections to cirrhosis and primary liver cancer worldwide. J Hepatol 2006;45:529-538.

3 Bosch FX, Ribes J, Cleries R, Diaz M: Epidemiology of hepatocellular carcinoma. Clin Liver Dis 2005;9:191211, v.

4 Zhang W, Sun B: Impact of age on the survival of patients with liver cancer: an analysis of 27, 255 patients in the SEER database. Oncotarget 2015;6:633-641.

-5 Venook AP, Papandreou C, Furuse J, de Guevara LL: The incidence and epidemiology of hepatocellular carcinoma: a global and regional perspective. Oncologist 2010;15 Suppl 4:5-13.

-6 Fan ST, Lo CM, Liu CL, Lam CM, Yuen WK, Yeung C, Wong J: Hepatectomy for hepatocellular carcinoma: toward zero hospital deaths. Ann Surg 1999;229:322-330.

7 Cha CH, Ruo L, Fong Y, Jarnagin WR, Shia J, Blumgart LH, DeMatteo RP: Resection of hepatocellular carcinoma in patients otherwise eligible for transplantation. Ann Surg 2003;238:315-321; discussion 321313.

-8 Poon RT, Fan ST, Lo CM, Ng IO, Liu CL, Lam CM, Wong J: Improving survival results after resection of hepatocellular carcinoma: a prospective study of 377 patients over 10 years. Ann Surg 2001;234:63-70.

-9 Cha C, Dematteo RP: Molecular mechanisms in hepatocellular carcinoma development. Best Pract Res Clin Gastroenterol 2005;19:25-37. 


\section{Cellular Physiology Cell Physiol Biochem 2018;46:2335-2346

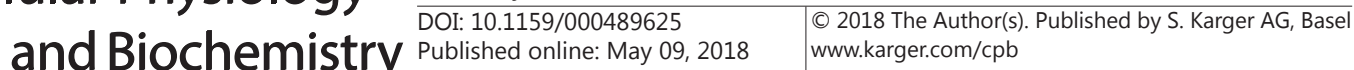 \\ Zhangyuan et al.: Prognostic Value of Ptps in HCC}

10 Kim JS, Shin OR, Kim HK, Cho YS, An CH, Lim KW, Kim SS: Overexpression of protein phosphatase nonreceptor type 11 (PTPN11) in gastric carcinomas. Dig Dis Sci 2010;55:1565-1569.

11 Saha S, Bardelli A, Buckhaults P, Velculescu VE, Rago C, St Croix B, Romans KE, Choti MA, Lengauer C, Kinzler KW, Vogelstein B: A phosphatase associated with metastasis of colorectal cancer. Science 2001;294:1343-1346.

12 Alonso A, Sasin J, Bottini N, Friedberg I, Friedberg I, Osterman A, Godzik A, Hunter T, Dixon J, Mustelin T: Protein tyrosine phosphatases in the human genome. Cell 2004;117:699-711.

13 Bard-Chapeau EA, Li S, Ding J, Zhang SS, Zhu HH, Princen F, Fang DD, Han T, Bailly-Maitre B, Poli V, Varki NM, Wang H, Feng GS: Ptpn11/Shp2 acts as a tumor suppressor in hepatocellular carcinogenesis. Cancer Cell 2011;19:629-639.

14 Sun T, Aceto N, Meerbrey KL, Kessler JD, Zhou C, Migliaccio I, Nguyen DX, Pavlova NN, Botero M, Huang J, Bernardi RJ, Schmitt E, Hu G, Li MZ, Dephoure N, Gygi SP, Rao M, Creighton CJ, Hilsenbeck SG, Shaw CA, Muzny D, Gibbs RA, Wheeler DA, Osborne CK, Schiff R, Bentires-Alj M, Elledge SJ, Westbrook TF: Activation of multiple proto-oncogenic tyrosine kinases in breast cancer via loss of the PTPN12 phosphatase. Cell 2011;144:703-718.

15 Luo RZ, Cai PQ Li M, Fu J, Zhang ZY, Chen JW, Cao Y, Yun JP, Xie D, Cai MY: Decreased expression of PTPN12 correlates with tumor recurrence and poor survival of patients with hepatocellular carcinoma. PLoS One 2014;9:e85592.

-16 Li J, Yen C, Liaw D, Podsypanina K, Bose S, Wang SI, Puc J, Miliaresis C, Rodgers L, McCombie R, Bigner SH, Giovanella BC, Ittmann M, Tycko B, Hibshoosh H, Wigler MH, Parsons R: PTEN, a putative protein tyrosine phosphatase gene mutated in human brain, breast, and prostate cancer. Science 1997;275:1943-1947.

17 Steck PA, Pershouse MA, Jasser SA, Yung WK, Lin H, Ligon AH, Langford LA, Baumgard ML, Hattier T, Davis T, Frye C, Hu R, Swedlund B, Teng DH, Tavtigian SV: Identification of a candidate tumour suppressor gene, MMAC1, at chromosome 10q23.3 that is mutated in multiple advanced cancers. Nat Genet 1997;15:356362.

18 Labbe DP, Hardy S, Tremblay ML: Protein tyrosine phosphatases in cancer: friends and foes! Prog Mol Biol Transl Sci 2012;106:253-306.

19 Mohi MG, Neel BG: The role of Shp2 (PTPN11) in cancer. Curr Opin Genet Dev 2007;17:23-30.

20 Camp RL, Dolled-Filhart M, Rimm DL: X-tile: a new bio-informatics tool for biomarker assessment and outcome-based cut-point optimization. Clin Cancer Res 2004;10:7252-7259.

21 Song C, Liu Y, Xu L, Wen J, Jiang D, Chen J, Zhai X, Hu Z, Liu L, Liu J: Hepatitis B virus mutations, expression quantitative trait loci for PTPN12, and their interactions in hepatocellular carcinoma. Cancer Med 2016;5:1687-1693.

22 Rhee I, Zhong MC, Reizis B, Cheong C, Veillette A: Control of dendritic cell migration, T cell-dependent immunity, and autoimmunity by protein tyrosine phosphatase PTPN12 expressed in dendritic cells. Mol Cell Biol 2014;34:888-899.

23 Manigold T, Racanelli V: T-cell regulation by CD4 regulatory T cells during hepatitis B and C virus infections: facts and controversies. Lancet Infect Dis 2007;7:804-813.

-24 El-Serag HB: Epidemiology of viral hepatitis and hepatocellular carcinoma. Gastroenterology 2012;142:1264-1273.e1261.

-25 Shen Q Fan J, Yang XR, Tan Y, Zhao W, Xu Y, Wang N, Niu Y, Wu Z, Zhou J, Qiu SJ, Shi YH, Yu B, Tang N, Chu W, Wang M, Wu J, Zhang Z, Yang S, Gu J, Wang H, Qin W: Serum DKK1 as a protein biomarker for the diagnosis of hepatocellular carcinoma: a large-scale, multicentre study. Lancet Oncol 2012;13:817-826.

-26 Nagasue N, Kohno H, Chang YC, Taniura H, Yamanoi A, Uchida M, Kimoto T, Takemoto Y, Nakamura T, Yukaya H: Liver resection for hepatocellular carcinoma. Results of 229 consecutive patients during 11 years. Ann Surg 1993;217:375-384.

27 Kamiyama T, Nakanishi K, Yokoo H, Kamachi H, Tahara M, Suzuki T, Shimamura T, Furukawa H, Matsushita M, Todo S: Recurrence patterns after hepatectomy of hepatocellular carcinoma: implication of Milan criteria utilization. Ann Surg Oncol 2009;16:1560-1571.

28 Zhang SQ, Yang W, Kontaridis MI, Bivona TG, Wen G, Araki T, Luo J, Thompson JA, Schraven BL, Philips MR, Neel BG: Shp2 regulates SRC family kinase activity and Ras/Erk activation by controlling Csk recruitment. Mol Cell 2004;13:341-355.

29 Easty D, Gallagher W, Bennett DC: Protein tyrosine phosphatases, new targets for cancer therapy. Curr Cancer Drug Targets 2006;6:519-532. 


\section{Cellular Physiology Cell Physiol Biochem 2018;46:2335-2346

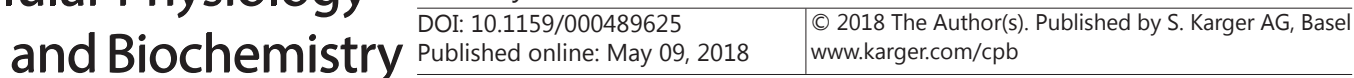 \\ Zhangyuan et al.: Prognostic Value of Ptps in HCC}

30 Cates CA, Michael RL, Stayrook KR, Harvey KA, Burke YD, Randall SK, Crowell PL, Crowell DN: Prenylation of oncogenic human PTP(CAAX) protein tyrosine phosphatases. Cancer Lett 1996;110:49-55.

-31 Van Renne N, Roca Suarez AA: miR-135a-5p-mediated downregulation of protein tyrosine phosphatase receptor delta is a candidate driver of HCV-associated hepatocarcinogenesis. 2017;10.1136/ gutjnl-2016-312270

-32 Hou J, Xu J, Jiang R, Wang Y, Chen C, Deng L, Huang X, Wang X, Sun B: Estrogen-sensitive PTPRO expression represses hepatocellular carcinoma progression by control of STAT3. Hepatology 2013;57:678-688.

-33 Villa-Moruzzi E: Tyrosine phosphatases in the HER2-directed motility of ovarian cancer cells: Involvement of PTPN12, ERK5 and FAK. Anal Cell Pathol (Amst) 2011;34:101-112.

34 Espejo R, Rengifo-Cam W, Schaller MD, Evers BM, Sastry SK: PTP-PEST controls motility, adherens junction assembly, and Rho GTPase activity in colon cancer cells. Am J Physiol Cell Physiol 2010;299:C454-463.

35 Cao X, Li Y, Luo RZ, He LR, Yang J, Zeng MS, Wen ZS: Tyrosine-protein phosphatase nonreceptor type 12 is a novel prognostic biomarker for esophageal squamous cell carcinoma. Ann Thorac Surg 2012;93:16741680.

-36 Lan MS, Modi WS, Xie H, Notkins AL: Assignment of the IA-2 gene encoding an autoantigen in IDDM to chromosome 2q35. Diabetologia 1996;39:1001-1002.

37 Notkins AL, Lan MS, Leslie RD: IA-2 and IA-2beta: the immune response in IDDM. Diabetes Metab Rev 1998;14:85-93.

-38 Gensler M, Buschbeck M, Ullrich A: Negative regulation of HER2 signaling by the PEST-type proteintyrosine phosphatase BDP1. J Biol Chem 2004;279:12110-12116.

-39 Lucs AV, Muller WJ, Muthuswamy SK: Shc is required for ErbB2-induced inhibition of apoptosis but is dispensable for cell proliferation and disruption of cell polarity. Oncogene 2010;29:174-187.

40 Veillette A, Rhee I, Souza CM, Davidson D: PEST family phosphatases in immunity, autoimmunity, and autoinflammatory disorders. Immunol Rev 2009;228:312-324.

-41 Lucci MA, Orlandi R, Triulzi T, Tagliabue E, Balsari A, Villa-Moruzzi E: Expression profile of tyrosine phosphatases in HER2 breast cancer cells and tumors. Cell Oncol 2010;32:361-372.

42 Demirci H, Reed D, Elner VM: Tissue-based microarray expression of genes predictive of metastasis in uveal melanoma and differentially expressed in metastatic uveal melanoma. J Ophthalmic Vis Res 2013;8:303307.

43 Guimaraes GS, Latini FR, Camacho CP, Maciel RM, Dias-Neto E, Cerutti JM: Identification of candidates for tumor-specific alternative splicing in the thyroid. Genes Chromosomes Cancer 2006;45:540-553.

44 Meir T, Dror R, Yu X, Qian J, Simon I, Pe'er J, Chowers I: Molecular characteristics of liver metastases from uveal melanoma. Invest Ophthalmol Vis Sci 2007;48:4890-4896. 